\title{
Genomic diversity of Areca Palm Velarivirus 1 (APV1) in Areca palm (Areca catechu) plantations in Hainan, China
}

\author{
Xianmei Cao, Ruibai Zhao, Hongxing Wang, Huaiwen Zhang, Xue Zhao, Latif Ullah Khan and Xi Huang*
}

\begin{abstract}
Background: Areca palm (Areca catechu L.) is an important commercial crop in southeast Asia, but its cultivation is threatened by yellowing leaf disease (YLD). Areca palm velarivirus 1 (APV1) was recently associated with YLD, but little is known regarding its population and genetic diversity. To assess the diversity of YLD, the APV1 genome was sequenced in YLD samples collected from different sites in Hainan.

Results: Twenty new and complete APV1 genomes were identified. The APV1 isolates had highly conserved sequences in seven open reading frames (ORFs; > 95\% nucleotide [nt] identity) at the $3^{\prime}$ terminal, but there was diversity (81-87\% nt identity) in three ORFs at the 5 ' terminal. Phylogenetic analysis divided the APV1 isolates into three phylogroups, with 16 isolates (> 70\%) in phylogroup A. Mixed infections with different genotypes in the same tree were identified; this was closely correlated with higher levels of genetic recombination.

Conclusions: Phylogroup A is the most prevalent APV1 genotype in areca palm plantations in Hainan, China. Mixed infection with different genotypes can lead to genomic recombination of APV1. Our data provide a foundation for accurate diagnostics, characterization of etiology, and elucidation of the evolutionary relationships of APV1 populations.
\end{abstract}

Keywords: Areca catechu, Yellowing leaf disease, APV1, Genetic diversity

\section{Introduction}

Yellowing leaf disease (YLD) was first associated with phytoplasma based on electron microscope observations and PCR amplification of the $16 \mathrm{~S}$ ribosomal RNA (rRNA) gene in India [1-3], China $[4,5]$, and Sri Lanka $[6,7]$. Areca palm velarivirus 1 (APV1) was first identified in an YLD leaf sample using RNA-sequencing (RNA-Seq) and was associated with YLD in a recent study [8, 9]. APV1 is a member of the genus Velarivirus (family Closteroviridae). APV1 has a typical flexuous, filamentous viral particle and a long, positive-sense, single-stranded RNA genome encoding 11 open reading

\footnotetext{
*Correspondence: xihuang@hainanu.edu.cn

Hainan Key Laboratory for Sustainable Utilization of Tropical Bioresources, College of Tropical Crops, Hainan University, Haikou 570228, Hainan, People's Republic of China
}

frames (ORFs). ORF1a encodes a large protein with papain-like proteinase (P-PRO), methyltransferase (MET), and helicase (HEL) domains, while ORF1b encodes a protein containing an RNA-dependent RNA polymerase (RdRp) domain; ORF1b is expressed with a frameshift of ORF1a. ORF2 encodes a 4-kDa hydrophobic protein. ORF3 encodes a $70-\mathrm{kDa}$ heat-shock protein 70 homolog (HSP70h) that partially overlaps ORF4, which encodes a 21-kDa polypeptide. ORF5 encodes a $60-\mathrm{kDa}$ protein. ORF6 and ORF7 encode the coat protein $(\mathrm{CP})$ and $\mathrm{CP}$ minor $(\mathrm{CPm})$, respectively, whereas ORF8, ORF9, and ORF10 encode 26-, 18- and 19-kDa polypeptides with unknown functions, respectively.

To date, the genomes of only two APV1 isolates have been determined. They showed high genetic diversity in the sequence and genome length. The genome of APV1-

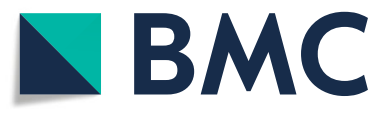

(c) The Author(s). 2021 Open Access This article is licensed under a Creative Commons Attribution 4.0 International License, which permits use, sharing, adaptation, distribution and reproduction in any medium or format, as long as you give appropriate credit to the original author(s) and the source, provide a link to the Creative Commons licence, and indicate if changes were made. The images or other third party material in this article are included in the article's Creative Commons licence, unless indicated otherwise in a credit line to the material. If material is not included in the article's Creative Commons licence and your intended use is not permitted by statutory regulation or exceeds the permitted use, you will need to obtain permission directly from the copyright holder. To view a copy of this licence, visit http://creativecommons.org/licenses/by/4.0/ The Creative Commons Public Domain Dedication waiver (http://creativecommons.org/publicdomain/zero/1.0/) applies to the data made available in this article, unless otherwise stated in a credit line to the data. 
WNY (MK956940) is 17,546 nt, whereas that of APV1HN (KR349464) is 16,080 nt, which was considered incomplete. Both isolates have similar genomic structures, although the $5^{\prime}$ terminal sequences show significant variation with only $83 \% \mathrm{nt}$ identity $[8,9]$. The lack of genomic sequences has hampered evaluation of the genetic diversity, pathogenicity, diagnostics, epidemiological characteristics, and evolutionary relationships of APV1. High-throughput sequencing (HTS) is a rapid, efficient, cost-effective platform for analyzing the genetic diversity of plant viruses and viroid genomes [10]. Here, HTS combined with RT-PCR amplification was used to detect YLD samples from different collection sites in Hainan Province. Twenty complete APV1 genome sequences were obtained. The sequences described here highlight the genetic diversity and phylogroups in the APV1 population. This has clear implications for accurate diagnostics, providing a foundation for elucidating the epidemiological characteristics and evolutionary relationships of APV1 populations.

\section{Materials and methods}

\section{Plant sample collection and RNA extraction}

Fifteen areca palm leaf samples with typical YLD symptoms were collected in the cities of Wanning and Qionghai, and in Lingshui, Tunchang, Baoting, and Ledong Counties in Hainan Province, China (Fig. S1). The samples were stored at $-80^{\circ} \mathrm{C}$ until RNA isolation.

\section{RNA-Seq and de novo assembly}

YLD leaves samples were ground separately in liquid nitrogen. Total RNA from each sample was isolated using
Tiangen plant RNA isolation kit according to the manufacturer's instructions (Tiangen Biotech, Beijing, China). RNA-Seq and de novo assembly were performed separately for each YLD sample, as described previously [9]. After annotation, the APV1 unigenes were selected. Gaps and terminals were amplified by RT-PCR using PrimeSTAR ${ }^{\bullet}$ GXL DNA Polymerase (TaKaRa, Dalian, China). The PCR products were incubated with Taq polymerase at $72{ }^{\circ} \mathrm{C}$ for $10 \mathrm{~min}$ and then ligated into the pMD-19 $\mathrm{T}$ vector (TaKaRa). Three independent positive clones of each fragment were subject to Sanger sequencing (Sangon Biotech, Guangzhou). Overlapping sequences were assembled into complete genomes using SeqMan Pro 7.1.0 (DNAStar Inc., Madison, WI, USA).

\section{Phylogenetic and sequence analysis of APV1}

For phylogenetic analysis, all full-length genome sequences obtained in this study were used, together with two APV1 sequences available in GenBank. The sequences were aligned using ClustalW with the default parameters and a phylogenetic tree was constructed using the neighbor-joining method with MEGA 7.0.

\section{Recombination analysis}

Recombination events were analyzed with the Recombination Detection Program (RDP v.4.95) under the default conditions, using an alignment of complete APV1 genome sequences constructed with MAFFT v7 [11].

Table 1 Summary of the RNA-Seq, de novo assembly, and APV1 isolate data of areca palm YLD samples

\begin{tabular}{lllllllll}
\hline Sample & Clean reads & Clean bases & Q30 (\%) & GC (\%) & Unigenes & APV1 unigenes & Longest APV1 unigenes & APV1 isolates identified \\
\hline Control & $112,977,362$ & $16.95 \mathrm{G}$ & 93.36 & 43.5 & 322,485 & 0 & 0 & $17,448 \mathrm{nt}$ \\
BTMT1 & $109,014,442$ & $16.35 \mathrm{G}$ & 93.64 & 44.25 & 375,447 & 9 & $17,440 \mathrm{nt}$ & BTMT1 \\
BTZL1 & $111,153,834$ & $16.67 \mathrm{G}$ & 93.48 & 44.3 & 307,293 & 8 & $17,515 \mathrm{nt}$ & BTZL1 \\
LDTT1 & $114,521,988$ & $17.18 \mathrm{G}$ & 93.57 & 43.84 & 409,421 & 9 & $17,530 \mathrm{nt}$ & LDT1 \\
LDT12 & $95,489,440$ & $14.32 \mathrm{G}$ & 93.3 & 43.96 & 360,780 & 9 & $9318 \mathrm{nt}$ & LDTT2 \\
LSGP1 & $92,771,398$ & $13.92 \mathrm{G}$ & 93.44 & 44.37 & 273,553 & 26 & $17,482 \mathrm{nt}$ & LSGP1-1; LSGP1-2; LSGP1-3 \\
LSGP2 & $97,687,560$ & $14.65 \mathrm{G}$ & 93.52 & 43.72 & 290,986 & 8 & $17,435 \mathrm{nt}$ & LSGP2 \\
QHDH1 & $89,537,286$ & $13.43 \mathrm{G}$ & 94.09 & 44.53 & 324,586 & 13 & $17,438 \mathrm{nt}$ & QHDH1 \\
QHDH4 & $80,108,502$ & $12.02 \mathrm{G}$ & 93.64 & 44.03 & 260,972 & 13 & $17,481 \mathrm{nt}$ & QHDH4 \\
QHZY1 & $87,295,496$ & $13.09 \mathrm{G}$ & 93.78 & 45.27 & 322,034 & 13 & $17,438 \mathrm{nt}$ & QHZY1 \\
QHZY2 & $95,210,422$ & $14.28 \mathrm{G}$ & 93.76 & 43.87 & 318,040 & 12 & $17,501 \mathrm{nt}$ & QHZY2 \\
TCFM1 & $115,107,346$ & $17.27 \mathrm{G}$ & 93.56 & 44.96 & 363,079 & 9 & $8866 \mathrm{nt}$ & TCFM1 \\
WNCF1 & $98,937,520$ & $14.84 \mathrm{G}$ & 93.25 & 43.77 & 345,757 & 31 & $17,437 \mathrm{nt}$ & WNCF1-1, 1-2, and 1-3 \\
WNLG1 & $122,943,318$ & $18.44 \mathrm{G}$ & 93.42 & 44.19 & 338,253 & 8 & $17,434 \mathrm{nt}$ & WNLG1 \\
WNSG1 & $82,280,618$ & $12.34 \mathrm{G}$ & 93.46 & 44.38 & 312,624 & 6 & $17,482 \mathrm{nt}$ & WNSG1 \\
WNXL1 & $98,334,604$ & $14.75 \mathrm{G}$ & 93.14 & 43.7 & 394,940 & 31 & & WNXL1-1, WNXL1-2 \\
\hline
\end{tabular}


Evaluation of primers for the detection of APV1

To identify a primer pair with a broad detection range, all reported primers for detecting the virus were compared in silico with APV1 complete genome sequences.

\section{Results}

\section{RNA-Seq and APV1 genome assembly}

Fifteen separate YLD samples were subjected to RNA extraction and RNA-Seq. Following de novo assembly of the sequence reads using Trinity, with an overlap length of $\mathrm{k}$-mer $=25$ [12], BlastN and BlastX analyses (cut-off value $=10^{-3}$ ) revealed APV1 unigenes in each YLD sample. Thirteen assembled APV1 unigenes were longer than 17,000 nt, which almost cover the complete APV1 genome sequences $(17,546 \mathrm{nt})$ (Table 1). The fullgenome sequences were determined by RT-PCR amplification of the gaps and terminal ends: 20 new complete genome sequences of APV1 isolates were identified. Interestingly, more than one different APV1 isolate was identified in each of three YLD samples (WNXL1, LSGP1, and WNCF1). The APV1 genome sequences were deposited in GenBank under accession numbers MW316004-MW316024. Previously, we used two YLD samples (WNY and BTY) for RNA-Seq [9], but only the genome of WNY isolate was determined. Here, the complete genome of the BTY isolate was determined through RT-PCR and rapid amplification of cDNA ends (RACE). Both isolates have the same 17,564 nt genome length, and identical 5'-UTR (48 nt) and 3'-UTR (225 nt) lengths. Furthermore, both isolates share a highly conserved 3'-UTR (99.6\% nt identity) and seven ORFs (ORF4 to ORF10) at the 3' terminal (97.6\% nt identities). However, notable sequence variation was observed at ORF1a (81.0\% nt and $81.6 \%$ aa identities), suggesting that it belongs to different genotypes.

\section{Genome organization and sequence similarities of the new APV1 isolates}

All the newly identified APV1 isolates have 11 ORFs and share identical genome organization with the reported WNY and APV1-hn isolates. Sixteen new isolates shared $90 \%$ nt genome identity with isolate APV1-WNY, with the greatest sequence variation seen in three ORFs at the 5' terminal (ORF1a, ORF1b, and ORF2), whereas the eight ORFs at the 3' terminal (ORF3 to ORF10) had high nt and amino acid (aa) similarity (Table 2). Despite the significant nt variation ( $87 \% \mathrm{nt}$ identity), the aa sequences of ORF1b (encoding RdRp) were conserved ( $\geq$ 94\% aa identity) between WNY and these isolates. Three isolates (LSGP1-3, WNCF1-3, and WNXL1-2) had the

Table 2 Nucleotide (amino acid) identity (\%) between APV1-WNY and the new APV1 isolates

\begin{tabular}{|c|c|c|c|c|c|c|c|c|c|c|c|c|c|}
\hline Isolates & Accession No & Full genome & ORF1a (PRO, MET, HEL) & $\begin{array}{l}\text { ORF1b } \\
\text { (RdRp) }\end{array}$ & $\begin{array}{l}\text { ORF2 } \\
\text { (P4) }\end{array}$ & $\begin{array}{l}\text { ORF3 } \\
\text { (HSP70) }\end{array}$ & $\begin{array}{l}\text { ORF4 } \\
\text { (P21) }\end{array}$ & $\begin{array}{l}\text { ORF5 } \\
\text { (P60) }\end{array}$ & $\begin{array}{l}\text { ORF6 } \\
\text { (CP) }\end{array}$ & $\begin{array}{l}\text { ORF7 } \\
(\mathrm{CPm})\end{array}$ & $\begin{array}{l}\text { ORF8 } \\
(P 26)\end{array}$ & $\begin{array}{l}\text { ORF9 } \\
\text { (P18) }\end{array}$ & $\begin{array}{l}\text { ORF10 } \\
\text { (P19) }\end{array}$ \\
\hline APV1-HN & KR349464 & - & - & $87(94)$ & $86(78)$ & $96(98)$ & $98(98)$ & $97(97)$ & $99(99)$ & $97(95)$ & $98(99)$ & $98(95)$ & - \\
\hline BTMT1 & MW316004 & 90 & $81(82)$ & $87(94)$ & $86(75)$ & $96(98)$ & $98(98)$ & $98(98)$ & 99 (99) & $97(97)$ & $98(99)$ & $98(95)$ & $97(97)$ \\
\hline BTY & MW316018 & 90 & $81(82)$ & $87(94)$ & $86(75)$ & $96(98)$ & $98(98)$ & $98(98)$ & $99(99)$ & $97(95)$ & $98(99)$ & $98(95)$ & $97(97)$ \\
\hline BTZL1 & MW316019 & 90 & $81(82)$ & $87(94)$ & $86(75)$ & $96(98)$ & $98(98)$ & $98(98)$ & 99 (99) & $97(95)$ & $98(99)$ & $98(95)$ & $97(97)$ \\
\hline LDTT1 & MW316005 & 90 & $81(82)$ & $87(94)$ & $85(75)$ & $96(98)$ & $98(98)$ & $97(98)$ & $98(99)$ & $97(96)$ & $99(99)$ & $97(95)$ & $98(97)$ \\
\hline LDTT2 & MW316006 & 90 & $81(82)$ & $87(94)$ & $85(75)$ & $96(98)$ & $98(98)$ & $97(98)$ & $98(98)$ & 97 (96) & 99 (99) & 97 (95) & $98(98)$ \\
\hline LSGP1-1 & MW316007 & 90 & $81(82)$ & 87 (94) & $86(75)$ & $96(98)$ & $98(98)$ & $98(98)$ & 98 (99) & 97 (95) & 99 (100) & 99 (99) & 99 (99) \\
\hline LSGP1-2 & MW316020 & 94 & $91(90)$ & $92(98)$ & $86(75)$ & 97 (98) & $98(98)$ & $98(98)$ & 99 (99) & 97 (95) & $97(98)$ & $98(95)$ & 99 (99) \\
\hline LSGP1-3 & MW316023 & 98 & $100(99)$ & $92(98)$ & $86(75)$ & 97 (98) & $98(98)$ & 98 (98) & 99 (99) & 97 (95) & 97 (99) & $98(95)$ & 99 (99) \\
\hline LSGP2 & MW316008 & 90 & $81(82)$ & 87 (94) & $84(72)$ & 97 (99) & $98(98)$ & $98(98)$ & $98(99)$ & 97 (96) & $99(100)$ & 97 (95) & $98(97)$ \\
\hline QHDH1 & MW316009 & 90 & $81(82)$ & 87 (94) & 85 (75) & $96(98)$ & $98(98)$ & $98(98)$ & 98 (98) & 97 (96) & $98(100)$ & $98(96)$ & $98(97)$ \\
\hline QHDH4 & MW316010 & 90 & $81(82)$ & 87 (94) & 85 (75) & $96(98)$ & $98(98)$ & $98(98)$ & 99 (99) & $97(96)$ & $98(100)$ & $98(96)$ & $98(97)$ \\
\hline QHZY1 & MW316011 & 90 & $81(82)$ & 87 (94) & $84(72)$ & 96 (99) & $98(98)$ & 97 (97) & $98(99)$ & 97 (96) & 99 (100) & 97 (94) & $98(97)$ \\
\hline QHZY2 & MW316012 & 90 & $81(82)$ & 87 (94) & $85(75)$ & $96(99)$ & $98(98)$ & 97 (97) & 98 (99) & 97 (96) & 99 (100) & $97(94)$ & $98(97)$ \\
\hline TCFM1 & MW316013 & 90 & $81(82)$ & 87 (94) & 85 (75) & 96 (99) & 98 (99) & 98 (98) & $98(99)$ & $98(98)$ & 99 (100) & 99 (99) & $98(96)$ \\
\hline WNCF1-1 & MW316014 & 90 & $81(82)$ & 87 (94) & $84(72)$ & 97 (99) & 98 (99) & $98(98)$ & 99 (99) & $97(96)$ & $99(100)$ & 99 (99) & 99 (99) \\
\hline WNCF1-2 & MW316021 & 95 & $91(90)$ & $92(97)$ & $86(72)$ & 99 (99) & $98(100)$ & $99(100)$ & $98(99)$ & $98(96)$ & $98(99)$ & 99 (99) & 99 (99) \\
\hline WNCF1-3 & MW316024 & 98 & 99 (99) & $92(97)$ & $86(72)$ & 99 (99) & $99(100)$ & 99 (100) & $98(99)$ & $98(96)$ & $99(100)$ & 99 (99) & 99 (99) \\
\hline WNLG1 & MW316015 & 90 & $81(82)$ & 87 (95) & $85(75)$ & $96(99)$ & $98(98)$ & 97 (97) & $98(98)$ & 97 (96) & $99(100)$ & $98(95)$ & $98(97)$ \\
\hline WNSG1 & MW316016 & 90 & $81(82)$ & $87(94)$ & $85(75)$ & 96 (99) & $98(98)$ & 97 (97) & $98(98)$ & 97 (96) & $99(100)$ & $98(95)$ & $98(97)$ \\
\hline WNXL1-1 & MW316017 & 90 & $81(82)$ & 87 (94) & $84(72)$ & 97 (99) & $98(98)$ & 98 (98) & $98(99)$ & $97(96)$ & 99 (100) & $98(95)$ & $98(98)$ \\
\hline WNXL1-2 & MW316022 & 98 & 99 (99) & $99(100)$ & $88(78)$ & 97 (99) & $98(98)$ & $98(98)$ & $98(98)$ & $97(96)$ & 99 (100) & $98(95)$ & $98(98)$ \\
\hline
\end{tabular}




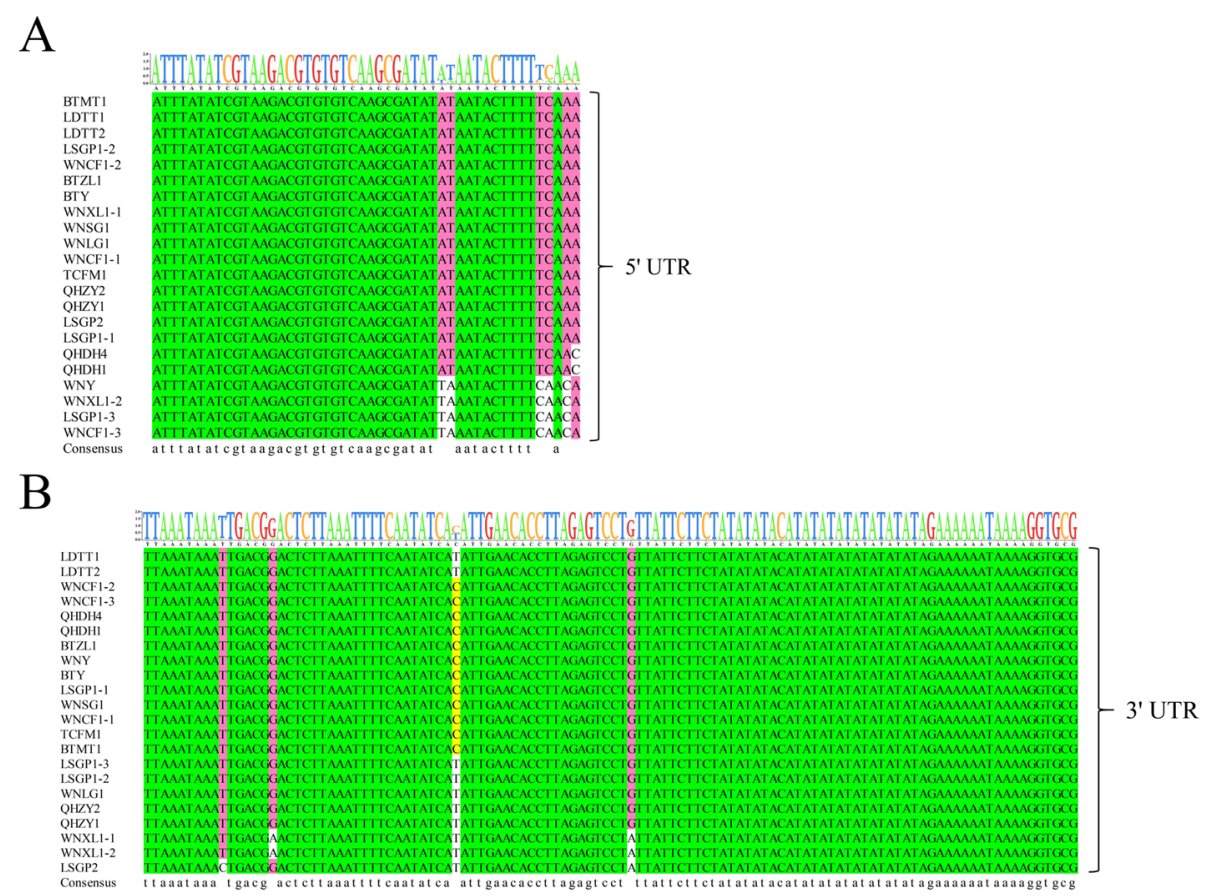

Fig. 1 Alignment of the 5' untranslated region (UTR) (48-nt) and part of the $3^{\prime}-$ UTR (113-nt)

highest entire genome nt similarity (98\% genomic nt identity) with isolate WNY, whereas isolates LSGP1-2 and WNCF1-2 had 94 and 95\% identity, respectively. These isolates were collected from two adjacent regions, Wanning City or Lingshui County. Interestingly, mixed infections with different APV1 genotypes were identified in samples LSGP1, WNCF1, and WNXL1 (Table 2). No indels or insert polymorphisms were found in any isolate. The 5' - and 3'-UTR nts were relatively conserved among the APV1 isolates (Fig. 1). Additionally, to identify a primer pair with a broader detection range, a primer set CPnew based on APV1 CP consensus sequences (with no SNP in 23 known APV1 isolates) was designed for diagnosing various APV1 isolates. (CPnew-F: 5' ATCGCTAAATATTATGGATAGACTT-3'; CPnew-R: 5'-TATTCAGAAGCATAAGATTGTGACA-3'). All the previously reported primers for detecting the virus were compared in silico with 20 APV1 complete genome sequences [9], the SNPs of each primers were shown in Figure S2. Finally, Twenty areca palm leafs samples were collected from different plantation areas of Hainan and RT-PCR was used to detect the presence of APV1. The detection rates are highly dependent on the SNP number. The primer sets with no SNP show higher detection rates and primer set with most SNP (YLDV1 and YLDV6) show lower detection efficiency (Figure S3), indicating that the primers based on consensus sequences have a broader detection range.

\section{Phylogenetic analysis of APV1 isolates}

To reveal the evolutionary relationships of the APV1 isolates, phylogenetic trees were constructed using either the full genome or ORF1a nt sequence (Fig. 2A). In the phylogenetic tree based on the full-genome nt sequences, the isolates clustered into three phylogroups. Sixteen APV1 isolates with evident sequence variation from isolate WNY were grouped in phylogroup A; the isolates with the highest sequence similarities to isolate WNY (LSGP1-3, WNCF1-3, WNXL1-2, and WNY) formed phylogroup C, and the remaining isolates (LSGP1-2 and WNCF1-2) formed phylogroup B. Three isolates identified from sample LSGP1 (LSGP1-1, LSGP1-2, and LSGP1-3) and three from sample WNCF1 (WNCF1-1, WNCF1-2, and WNCF1-3), were separated into three different phylogroups. Two isolates from sample WNXL1 (WNXL1-1 and WNXL1-2) were in phylogroups A and $\mathrm{C}$, respectively. Phylogroup $\mathrm{B}$ consisted of two isolates (LSGP1-2 and WNCF1-2) located between phylogroups $A$ and $C$, suggesting that the phylogroup $\mathrm{B}$ is a genotype derived from recombination between phylogroups A and C (Fig. 2A). Because ORF1a shows most significant sequence variation among the APV1 isolates, nt sequences of ORF1a were selected for phylograph clustering. The phylogenetic tree based on ORF1a resulted in similar phylogroup clustering (Fig. 2B), indicating that the sequence variation in 


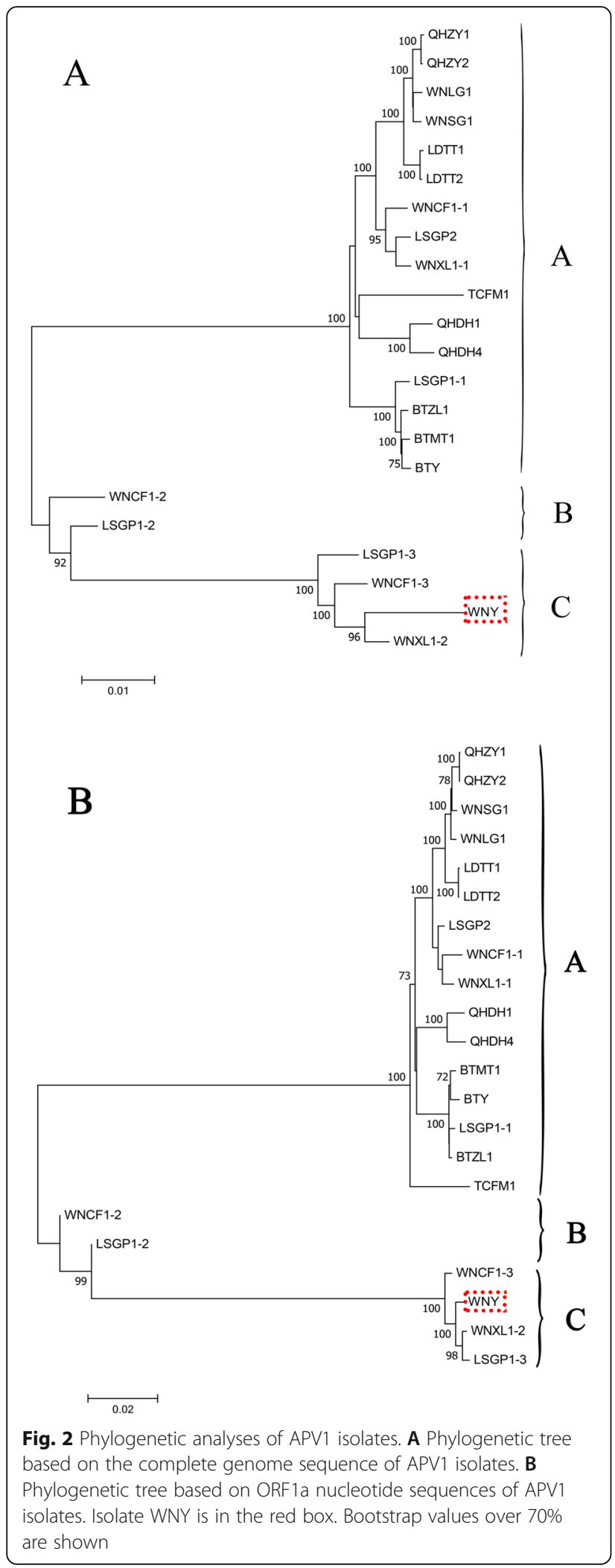

ORF1a represents the genetic diversity among the APV1 isolates.

\section{Recombination analysis}

To investigate the evolutionary relationships of the APV1 populations, recombination analysis was performed with RDP4 [11] using different algorithms (RDP, GENECONV, BootScan, MaxChi, Chimaera, and 3Seq) on an alignment of all full-length APV1 genome sequences. RDP4 revealed 20 recombination events from 22 viral genomes, of which, 15 recombination events was detected in the isolates from mixed infection samples (LSGP1, WNCF1, and WNXL1) (Table 3), strongly suggesting that co-infection with different APV1 genotypes leads to genetic recombination. On examining the recombination events in isolates WNCF1-2 and LSGP1-2 (clustered into phylogroup B), WNCF1-1 and BTY were revealed as the parental isolates of WNCF1-2, while BTY and LSGP1-1 were the parental isolates of LSGP12 , indicating that the major combination source come from co-infected APV1 isolates (Fig. 3), suggesting that sequence diversity among different APV1 phylogroups contributes to genetic recombination. Furthermore, when we marked the collected sites and APV1 isolates on map, we can clearly see that the major recombination correlated isolates, such as BTY, WNCF1-2, WNXL1-2 and LSGP1-2 variants are geographical neighbor (Fig. S1), suggesting a correlation between geographical distance and recombination events.

\section{Discussion}

Little is known regarding the population and genetic diversity of APV1. HTS technology enables the discovery and identification of unknown viral genome sequences $[13,14]$. Here, HTS was used to investigate the genetic diversity of APV1 in areca palm plantations in Hainan, China. In total, 20 new APV1 complete genomes were identified. From 15 YLD samples collected in Hainan, 12 were infected by a single APV1 isolate and 3 showed mixed infection by two or three different APV1 isolates. Co-infection by different viral genotypes within the same host have been reported in many crops and viruses [10, $13,15,16]$. In this study, recombination analysis first revealed a correlation between a high recombination rate and mixed infections of APV1 isolates (Fig. 2 and Table 3). Furthermore, the isolates of phylogroup B might have resulted from genetic recombination of coinfecting isolates from phylogroups $\mathrm{A}$ and $\mathrm{C}$ (Figs. 2A and 3 ). These results provide very important evidences of the evolutionary relationships of APV1 populations.

The classification of viral species is usually based on molecular and biological characteristics, as well as phylogenetic relationships. The sequence divergence criterion for species demarcation within the family Closteroviridae 
Table 3 Recombination events predicted by RDP4 in the full genomes of the 22 APV1 isolates

\begin{tabular}{|c|c|c|c|c|c|c|c|c|c|c|}
\hline \multirow{2}{*}{$\begin{array}{l}\text { Event } \\
\text { No. }\end{array}$} & \multirow[t]{2}{*}{ Recombination } & \multirow[t]{2}{*}{ Major parent } & \multirow[t]{2}{*}{ Minor parent } & \multicolumn{7}{|c|}{ Detection methods } \\
\hline & & & & $\mathbf{R}$ & G & B & $M$ & C & $S$ & $T$ \\
\hline 1 & LSGP1-1 & BTZL1 & Unknown (WNLG1) & + & + & - & - & - & - & - \\
\hline 2 & LSGP1-2 & LSGP1-1 & Unknown (WNXL1-2) & - & + & - & + & + & - & + \\
\hline 3 & LSGP1-3 & WNY & LSGP1-1 & - & + & - & - & - & + & + \\
\hline 4 & LSGP1-3 & Unknown (TCFM1) & BTY & + & + & - & - & - & - & - \\
\hline 5 & LSGP1-3 & WNY & BTY & + & + & - & + & + & + & + \\
\hline 6 & LSGP2 & WNXL1-1 & QHZY1 & + & + & - & + & + & - & - \\
\hline 7 & $\mathrm{QHDH} 4$ & QHZY1 & QHDH1 & - & - & - & + & + & - & - \\
\hline 8 & QHZY1 & LSGP2 & Unknown (QHDH1) & - & - & - & + & + & - & - \\
\hline 9 & TCFM1 & BTZL1 & WNY & + & - & - & + & + & - & - \\
\hline 10 & WNCF1-1 & WNXL1-1 & Unknown (QHZY1) & - & - & - & + & - & - & + \\
\hline 11 & WNCF1-2 & WNCF1-3 & BTY & + & + & - & + & + & + & + \\
\hline 12 & WNCF1-3 & WNY & LSGP2 & + & + & - & + & + & + & + \\
\hline 13 & WNCF1-3 & Unknown (WNLG1) & WNCF1-1 & + & + & - & + & + & - & - \\
\hline 14 & WNCF1-3 & WNY & WNXL1-1 & + & + & - & + & + & - & - \\
\hline 15 & WNCF1-3 & WNY & WNXL1-1 & + & + & - & + & - & + & - \\
\hline 16 & WNSG1 & LDTT1 & BTZL1 & + & - & - & + & + & - & - \\
\hline 17 & WNXL1-2 & WNY & WNXL1-1 & + & - & - & - & - & + & - \\
\hline 18 & WNXL1-2 & Unknown (TCFM1) & WNXL1-1 & + & + & - & - & - & + & - \\
\hline 19 & WNXL1-2 & Unknown (QHDH1) & WNXL1-1 & + & + & - & - & - & - & - \\
\hline 20 & WNXL1-2 & WNY & LSGP2 & + & + & - & + & + & + & + \\
\hline
\end{tabular}

was increased from 10 to $25 \%$ for phylogenetically informative proteins (e.g., RdRp, HSP70h, or CP) [17]. Based on this criterion, all of the isolates identified herein belong to species APV1. The isolates clustered into three different phylogenetic groups based on complete genome sequences. The genetic variation that differentiated the three APV1 phylogroups was concentrated in three $5^{\prime}$-terminal ORFs, whereas the eight $3{ }^{\prime}$ terminal ORFs had high sequence similarity. ORF1a shows most significant sequence variation among the APV1 isolates (Table 2). The phylogenetic tree based on ORF1a resulted in similar phylogroup clustering (Fig. 2B), variation of ORF1a is the representative genetic diversity of APV1 isolates. Instead of the entire genome, ORF1a could be selected for the target of APV1 genetic diversity in the future study, which could save time and money.

Through phylogenetic analysis, phylogroup A was found to be the most prevalent genotype in areca palm plantations in Hainan, China, but the reasons are so far less known. Characterization of the association between epidemiological characteristics and genotypes, and identification of the interaction between the different genotypes and insect vectors might be required for the characterization of etiology and propagation of the disease.
Sequence comparisons of all available APV1 isolates showed high conservation in the $5^{\prime}$-UTR, and in most of the $3^{\prime}$-UTR. While there were several single nt polymorphisms, no indel polymorphisms were identified in either UTR region for any APV1 isolate. The 3'-UTR of positive-strand RNA viruses generally contains regulatory sequences essential for both host protein binding and viral multiplication $[18,19]$. Sequence conservation in the 3'-UTR might be required for efficient APV1 viral replication. Most positive-strand RNA plant viruses lack the $5^{\prime}$-cap or the poly(A)-tail, which act synergistically to stimulate the canonical translation of cellular mRNAs. However, they have RNA elements in the $5^{\prime}$ - or $3^{\prime}$ UTRs, which are required for cap-independent translation [20]. Citrus tristeza virus (CTV) is a well-studied member of Closteroviridae. Many CTV isolates share similar 5'-UTR structures with two long stem loops, which are the primary determinants of recognition and the initiation of replication [21]. APV1 $5^{\prime}$-UTR is shorter than the CTV 5'-UTR; the secondary structures are also very different, suggesting that a different mechanism regulates viral replication in APV1.

Consensus among the eight 3 '-terminal ORFs enabled us to design PCR primers for diagnosing various APV1 isolates. The nt and aa sequences of ORF6 (CP), ORF7 


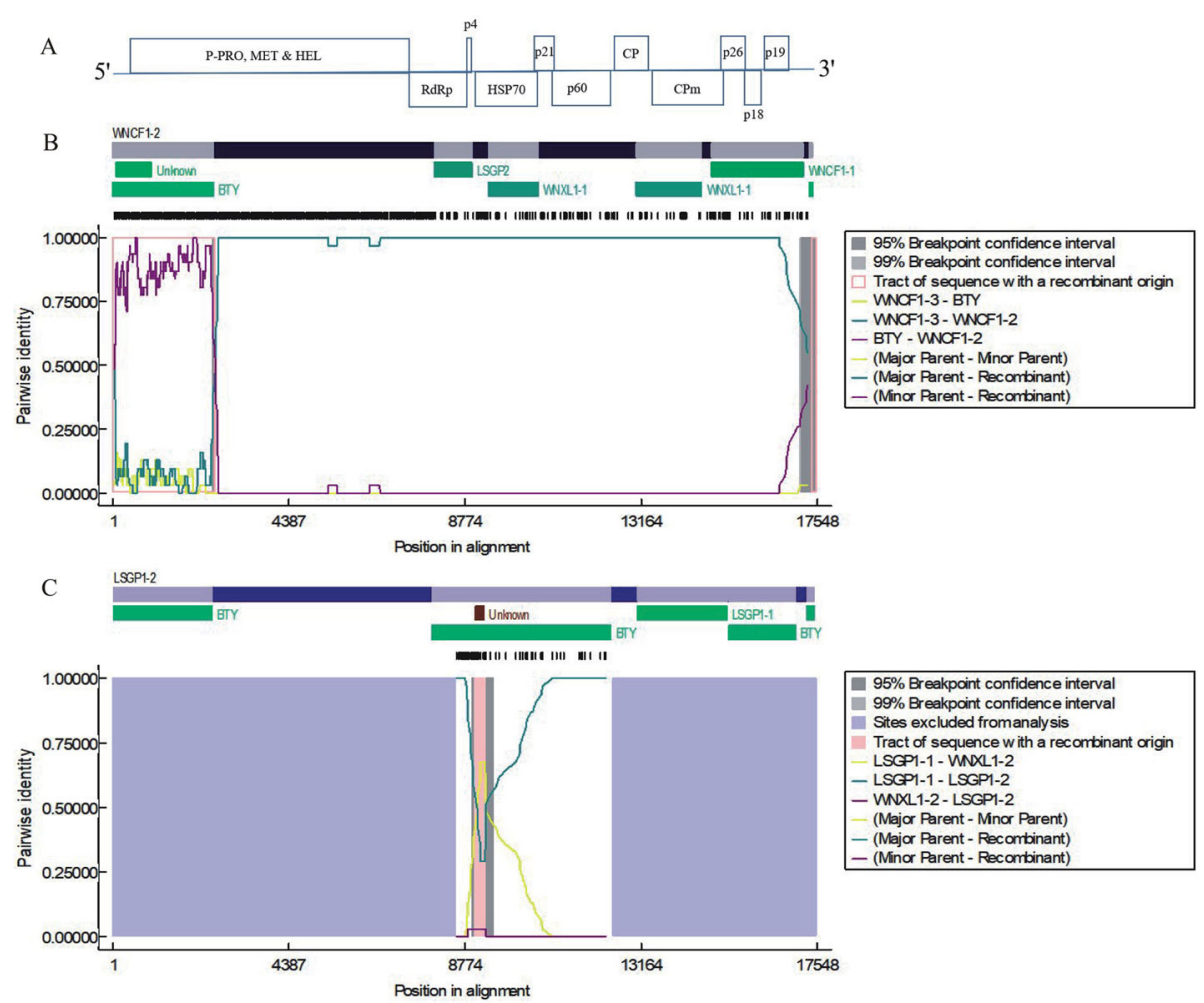

Fig. 3 Recombination events predicted by RDP4. A Schematic of the APV1 genome organization. The positions of identified recombinants are shown along with the names of the parental sequences. The individual genome of the APV1 isolate is indicated by different colored bars. The identified recombination events, including WNCF1-2 (B) and LSGP1-2 (C), were rechecked using RDP4 and plotted with pairwise identity information

$(\mathrm{CPm})$, and ORF8 (P26) are very similar across the isolates, and constitute optimal targets for engineering virus-resistant plants, such as by over-expression of RNA interference (RNAi), artificial microRNAs (amiRNAs), synthetic trans-acting small interfering RNAs (syn-tasiRNAs) [22-25], CRISPR [26, 27], and virusbased vaccines $[28,29]$. However, these methods all depend on Agrobacterium or virus-mediated transformation, neither of which is available for areca palm.

Future research should examine the epidemiological characteristics of different APV1 genotypes, which might help to identify a mild isolate. Pre-inoculation with a mild isolate has successfully induced cross-protection against virulent isolates of many plant viruses [30, 31]. We also plan to construct a wild-type infectious clone, and to create a mild infectious clone by attenuating the APV1 genome.

\section{Supplementary Information}

The online version contains supplementary material available at https://doi. org/10.1186/s12864-021-07976-6.

\section{Additional file 1}

\section{Acknowledgements}

This work is dedicated to the memory of my father, Tiancheng Huang (1943-2019).

\section{Authors' contributions}

X.H. conceived and designed the experiments; X.C., R.Z., H.Z., and X.Z. performed the experiments; H.W. and L.U.K. analyzed the data; X.C. wrote the paper; L.U.K. and X.H. revised the paper. All authors discussed the results and contributed to the final manuscript.

\section{Funding}

This study was supported financially by the Hainan Major Research Project for Science and Technology (grant no. ZDYF2021XDNY189).

\section{Availability of data and materials}

The complete APV1 genome sequences were deposited in GenBank with respective accession numbers MW316004-MW316024 and the datasets used and/or analysed during the current study available from the corresponding author on reasonable request.

\section{Declarations}

Ethics approval and consent to participate

This study did not include the use of any animals, human or otherwise, so did not require ethical approval. The collection of leaf samples and use in the study are complying with relevant institutional, national, and international guidelines.

\section{Consent for publication}

Not applicable.

\section{Competing interests}

The authors declare that they have no competing interest. 
Received: 17 March 2021 Accepted: 30 August 2021

Published online: 07 October 2021

\section{References}

1. Manimekalai R, Deeshma KP, Manju KP, Soumya VP, Sunaiba M, Nair S, et al. Molecular marker-based genetic variability among Yellow Leaf Disease (YLD) resistant and susceptible arecanut (Areca catechu L.) genotypes. Indian J Hortic. 2012;69(4):455-61.

2. Nayar R, Seliskar CE. Mycoplasma like organisms associated with yellow leaf disease of Areca catechu L. Eur J For Pathol. 1978;8(2):125-8.

3. Ramaswamy M, Nair S, Soumya VP, Thomas GV. Phylogenetic analysis identifies a 'Candidatus Phytoplasma oryzae'-related strain associated with yellow leaf disease of areca palm (Areca catechu L.) in India. Int J Syst Evol Microbiol. 2013;63(Pt 4):1376-82.

4. Luo DQ, Chen MR, Ye SB, Tsai JH. Identification of pathogens of yellow leaf disease of arecanut in Hainan Island. Chin J Trop Crops. 2001;22(2):43-6.

5. Che HY, Wu CT, Fu RY, Wen YS, Ye SB, Luo DQ. Molecular identification of pathogens from arecanut yellow leaf disease in Hainan. Chin J Trop Crops. 2010;31(1):83-7.

6. Abeysinghe $S$, Abeysinghe PD, Kanatiwela-de Silva C, Udagama $P$, Warawichanee K, Aljafar N, et al. Refinement of the taxonomic structure of $16 \mathrm{SrXI}$ and 16SrXIV phytoplasmas of gramineous plants using multilocus sequence typing. Plant Dis. 2016;100(10):2001-10.

7. Kanatiwela-de Silva C, Damayanthi M, de Silva R, Dickinson M, de Silva N, Udagama P. Molecular and scanning electron microscopic proof of phytoplasma associated with areca palm yellow leaf disease in Sri Lanka. Plant Dis. 2015;99(11):1641.

8. Yu H, Qi S, Chang Z, Rong Q, Akinyemi IA, Wu Q. Complete genome sequence of a novel velarivirus infecting areca palm in China. Arch Virol. 2015;160(9):2367-70.

9. Wang H, Zhao R, Zhang H, Cao X, Li Z, Zhang Z, et al. Prevalence of yellow leaf disease (YLD) and its associated areca palm velarivirus 1 (APV1) in betel palm (Areca catechu) plantations in Hainan, China. Plant Dis. 2020;104(10): 2556-62.

10. Katsiani A, Maliogka VI, Katis N, Svanella-Dumas L, Olmos A, Ruiz-Garcia AB, et al. High-throughput sequencing reveals further diversity of little cherry virus 1 with implications for diagnostics. Viruses. 2018;10(7):385.

11. Martin DP, Murrell B, Golden M, Khoosal A, Muhire B. RDP4: detection and analysis of recombination patterns in virus genomes. Virus Evol. 2015;1(1): vev003.

12. Grabherr MG, Haas BJ, Yassour M, Levin JZ, Thompson DA, Amit I, et al. Fulllength transcriptome assembly from RNA-Seq data without a reference genome. Nat Biotechnol. 2011;29(7):644-52.

13. Xu Y, Li S, Na C, Yang L, Lu M. Analyses of virus/viroid communities in nectarine trees by next-generation sequencing and insight into viral synergisms implication in host disease symptoms. Sci Rep. 2019;9(1):12261.

14. Jo Y, Bae J-Y, Kim S-M, Choi H, Lee BC, Cho WK. Barley RNA viromes in six different geographical regions in Korea. Sci Rep. 2018;8:13237.

15. Tahzima R, Foucart Y, Peusens G, Belien T, Massart S, De Jonghe K. Highthroughput sequencing assists studies in genomic variability and epidemiology of little cherry virus 1 and 2 infecting Prunus spp. in Belgium. Viruses. 2019:11(7):592.

16. Mulabisana MJ, Cloete M, Laurie SM, Mphela W, Maserumule MM, Nhlapo TF, et al. Yield evaluation of multiple and co-infections of begomoviruses and potyviruses on sweet potato varieties under field conditions and confirmation of multiple infection by NGS. Crop Prot. 2019:119:102-12.

17. Martelli GP, Agranovsky AA, Bar-Joseph M, Boscia D, Candresse T, Coutts RHA, Dolja W, Hu JS, Jelkmann W, Karasev AV: Family closteroviridae. In: Virus taxonomy-ninth report of the international committee on taxonomy of viruses. Edited by King AMQ, Adams MJ, Carstens EB, Lefkowitz EJ. San Diego: Academic Press; 2011: 987-1001.

18. Prosser SW, Goszczynski DE, Meng B. Molecular analysis of double-stranded RNAs reveals complex infection of grapevines with multiple viruses. Virus Res. 2007;124(1-2):151-9

19. Sriskanda VS, Pruss G, Ge X, Vance VB. An eight-nucleotide sequence in the potato virus $X 3^{\prime}$ untranslated region is required for both host protein binding and viral multiplication. J Virol. 1996;70(8):5266-71.

20. Truniger V, Miras M, Aranda MA. Structural and functional diversity of plant virus 3'-cap-independent translation enhancers (3'-CITEs). Front Plant Sci. 2017:8:2047
21. Satyanarayana T, Gowda S, Boyko VP, Albiach-Marti MR, Mawassi M, NavasCastillo J, et al. An engineered closterovirus RNA replicon and analysis of heterologous terminal sequences for replication. Proc Natl Acad Sci U S A. 1999:96(13):7433-8

22. Carbonell A. Design and high-throughput generation of artificial small RNA constructs for plants. Methods Mol Biol. 1932;2019:247-60.

23. Carbonell A, Carrington JC, Daros JA. Fast-forward generation of effective artificial small RNAs for enhanced antiviral defense in plants. RNA Dis. 2016; 3(1):e1130.

24. Carbonell A, Daros JA. Artificial microRNAs and synthetic trans-acting small interfering RNAs interfere with viroid infection. Mol Plant Pathol. 2017;18(5): 746-53.

25. Carbonell A, Daros JA. Design, synthesis, and functional analysis of highly specific artificial small RNAs with antiviral activity in plants. Methods Mol Biol. 2019:2028:231-46.

26. Zhang T, Zhao Y, Ye J, Cao X, Xu C, Chen B, et al. Establishing CRISPR/ Cas13a immune system conferring RNA virus resistance in both dicot and monocot plants. Plant Biotechnol J. 2019;17(7):1185-7.

27. Zhang T, Zheng Q, Yi X, An H, Zhao Y, Ma S, et al. Establishing RNA virus resistance in plants by harnessing CRISPR immune system. Plant Biotechnol J. 2018;16(8):1415-23.

28. Yamagishi N, Yoshikawa N. Highly efficient virus-induced gene silencing in apple and soybean by apple latent spherical virus vector and biolistic inoculation. Methods Mol Biol. 2013;975:167-81.

29. Taki A, Yamagishi N, Yoshikawa N. Development of apple latent spherical virusbased vaccines against three tospoviruses. Virus Res. 2013;176(1-2):251-8.

30. Zhou C, Zhou Y. Strategies for viral cross protection in plants. Methods Mol Biol. 2012;894:69-81.

31. Folimonova SY. Developing an understanding of cross-protection by Citrus tristeza virus. Front Microbiol. 2013:4:76

\section{Publisher's Note}

Springer Nature remains neutral with regard to jurisdictional claims in published maps and institutional affiliations.
Ready to submit your research? Choose BMC and benefit from:

- fast, convenient online submission

- thorough peer review by experienced researchers in your field

- rapid publication on acceptance

- support for research data, including large and complex data types

- gold Open Access which fosters wider collaboration and increased citations

- maximum visibility for your research: over $100 \mathrm{M}$ website views per year

At BMC, research is always in progress.

Learn more biomedcentral.com/submissions 